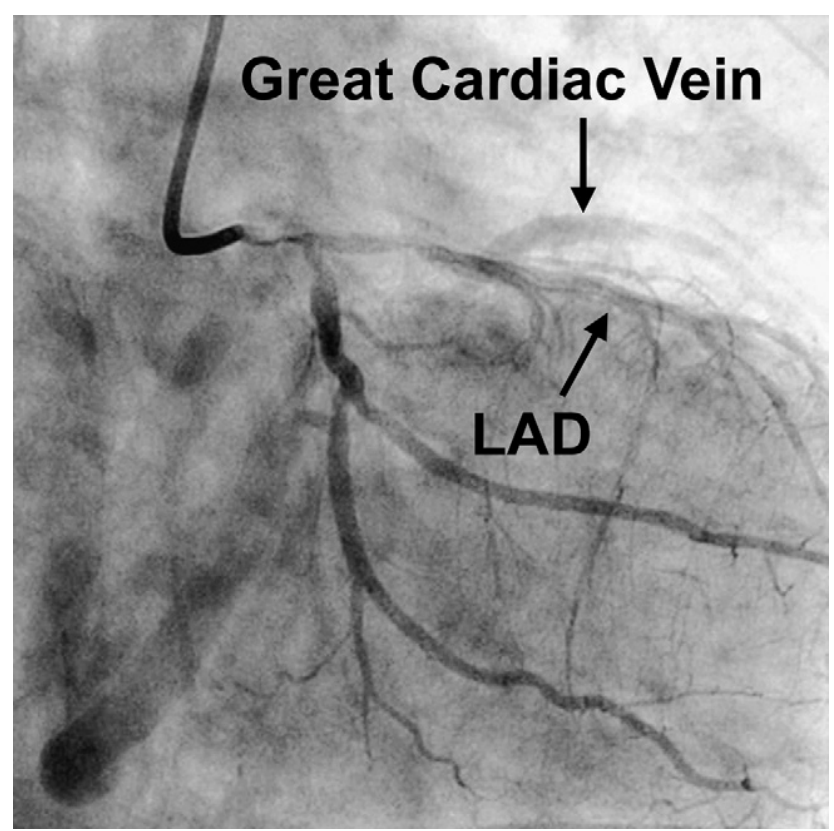

FIGURE 1. Significant separation between the LAD and great cardiac vein. $L A D$, left anterior descending coronary artery.

artery is suggested by a straight course and a systolic "milking effect" of myocardial fibers on the artery. ${ }^{1,2}$

We recently dealt with a right ventricular intracavitary LAD. We retrospectively recognized a significant separation between the LAD and the great cardiac vein, in the right anterior oblique view, at commencement of the venous phase of the selective left coronary angiogram (Figure 1). Although this entity will rarely be identified preoperatively, intraoperative review of the coronary angiogram can be of great value when the LAD is not found after superficial dissection. Recognition of an intracavitary LAD will prevent inadvertent entry into the right ventricle.

Familiarity with the coronary venous anatomy is important in identifying the non-obvious epicardial coronary arteries, especially with pericardial adhesions. ${ }^{3}$ On a coronary angiogram, depiction of the arterial and venous phase together is not common and depends on the amount and duration of contrast, radiation exposure, and coronary flow, among other factors. Even so, when depicted consecutively, mental superimposition of the arterial and venous phase can demonstrate the relation between the great cardiac vein and the LAD. Other methods to assist in intraoperatively locating an intramyocardial or intracavitary LAD are to trace back a distal or proximal LAD segment or branch, dissect on the right side of the great cardiac vein, palpate the (calcified) LAD, palpate an intraluminal probe inserted via a distal LAD or diagonal arteriotomy, or use a sterile epicardial Doppler ultrasound probe. ${ }^{1,2}$

Using a depiction of the great cardiac vein to recognize or suspect an intracavitary course of the LAD has not been reported before.

\section{References}

1. Ochsner JL, Mills NL. Surgical management of diseased intracavitary coronary arteries. Ann Thorac Surg. 1984;38:356-62.

2. Oz MC, Cooper MM, Hickey TJ, Rose EA. Exposure of the intramyocardial left anterior descending artery. Ann Thorac Surg. 1994;58:1194-5.

3. Cmolik BL, Geha AS. Coronary artery operations and reoperations, techniques and conduits. In: Baue AE, Geha AS, Hammond GL, Laks H, Naunheim KS, eds. Glenn's Thoracic and Cardiovascular Surgery. 6th ed. Stamford, CT: Appleton \& Lange; 1996:2081-92.

\title{
Management of aortobronchial fistula developing 27 years after open aortic surgery by means of endovascular stent grafting
}

\author{
Stefan Hacker, MD, ${ }^{\mathrm{a}}$ Herbert Langenberger, MD ${ }^{\mathrm{b}}$ Christina Plank, MD, ${ }^{\mathrm{b}}$ Michael Gorlitzer, MD, ${ }^{\mathrm{c}}$ \\ Marek Ehrlich, MD, ${ }^{\mathrm{a}}$ Werner Dolak, MD,${ }^{\mathrm{d}}$ Sören Kreuzer, MD, ${ }^{\mathrm{b}}$ Christian Loewe, MD, \\ Walter Klepetko, MD, ${ }^{\mathrm{a}}$ and Hendrik Jan Ankersmit, MD, ${ }^{\mathrm{a}}$ Vienna, Austria
}

\footnotetext{
From the Department of Surgery ${ }^{\mathrm{a}}$ and Radiology, ${ }^{\mathrm{b}}$ Medical University of Vienna, Vienna, Austria; Department of Cardiovascular Surgery, Hospital Hietzing, ${ }^{c}$ Vienna, Austria; and Department of Internal Medicine III, Medical University of Vienna, ${ }^{\mathrm{d}}$ Vienna, Austria.

Disclosures: None.

Received for publication Nov 26, 2008; accepted for publication Feb 20, 2009; available ahead of print April 27, 2009.

Address for reprints: Hendrik Jan Ankersmit, MD, Department of Cardiothoracic Surgery, Medical University of Vienna, Waehringer Guertel 18-20, 1090 Vienna, Austria (E-mail: hendrik.ankersmit@meduniwien.ac.at).

J Thorac Cardiovasc Surg 2010;139:778-80

$0022-5223 / \$ 36.00$

Copyright (c) 2010 by The American Association for Thoracic Surgery doi:10.1016/j.jtcvs.2009.02.036
}

Fistulous connections between the thoracic aorta and the bronchial systems are rare but potentially fatal complications. However, reports are limited and guidelines for diagnosis and treatment are not available. Most often, patients have a history of reconstructive vascular surgery followed by anastomotic aneurysm or dissection. Aortobronchial fistulas (ABFs) regularly present with mild to massive hemoptysis and chest pain. ${ }^{1}$ Given the high mortality of untreated patients, immediate patient management with either open surgery or endovascular repair is essential. We present the 
case of an ABF occurring 27 years after open surgical repair because of a false aortic aneurysm.

\section{CLINICAL SUMMARY}

A 52-year-old female patient reported to the emergency department with increasing volumes of hemoptysis. The patient had been experiencing increasing episodes of coughing followed by production of bloody sputum for the previous 10 days. During the last 48 hours, a significant aggravation of symptoms was noted by the patient.

At the age of 16 years, the patient had sustained multiple injuries after a traumatic car accident and was treated for ruptured diaphragm and spleen, as well as pelvic and maxillary fractures. The diaphragmatic defect was unsatisfactorily repaired. In addition, a false aneurysm of the descending aorta was diagnosed and observed. Growth of the aneurysm was slow, and elective vascular surgery with resection of the false aneurysm and implantation of a prosthesis with end-toend anastomosis was performed in 1981.

Proximal to the anastomosis, a dissection of the aortic wall was diagnosed at a routine follow-up examination in 2006, but the patient remained without clinical symptoms until 2008, 27 years after the initial surgical repair. Arterial blood pressure at the day of admission was $140 / 80 \mathrm{~mm} \mathrm{Hg}$. Initial chest computed tomography (CT) showed a perforating ulcus of the descending aorta in close proximity to the preexisting anastomosis with connection to the bronchial system, leading to the diagnosis of a secondary $\mathrm{ABF}$ (Figure 1, $A, B$ ). A smaller second lesion was identified at the inner curve of the aortic arch.
Immediate endovascular treatment with implantation of a stent graft was initiated. After surgical exposure of the left common femoral artery and insertion of a $4 F$ pigtail catheter via the right brachial artery, a stiff 0.035 -inch Back-up Meier guidewire (Boston Scientific, Natick, MA) was placed into the ascending aorta using a retrograde endovascular route. After baseline angiography (Figure 1,C), the patient received a Valiant Thoracic Stent Graft $28 / 28 \times 100 \mathrm{~mm}$ (Medtronic, Minneapolis, MN), and the covered part was placed distal of the left subclavian artery. Control angiography of the aortic arch disclosed successful exclusion of both ulcers (Figure 2, A). During the procedure, antibiotic prophylaxis with cefuroxime was commenced. After the intervention, the patient remained in the intensive care unit for another day and was transferred to the Department of Pneumology for further monitoring.

Recurring minor episodes of bloody expectorations ceased after 5 days. Administration of corticosteroids to prevent inflammation of the left lung was started. The postoperative course was uneventful with stable levels of hemoglobin and no other signs of bleeding. Follow-up CT showed optimal situation of the stent graft and complete thrombosis of the false lumen (Figure 2, $B, C$ ).

\section{DISCUSSION}

$\mathrm{ABFs}$ are a rare event with potentially fatal outcome. Early diagnosis and treatment are essential for survival. Patients with a history of aortic repair or aneurysms are considered to be at increased risk. In most cases, ABFs are localized between the descending aorta and the left bronchial
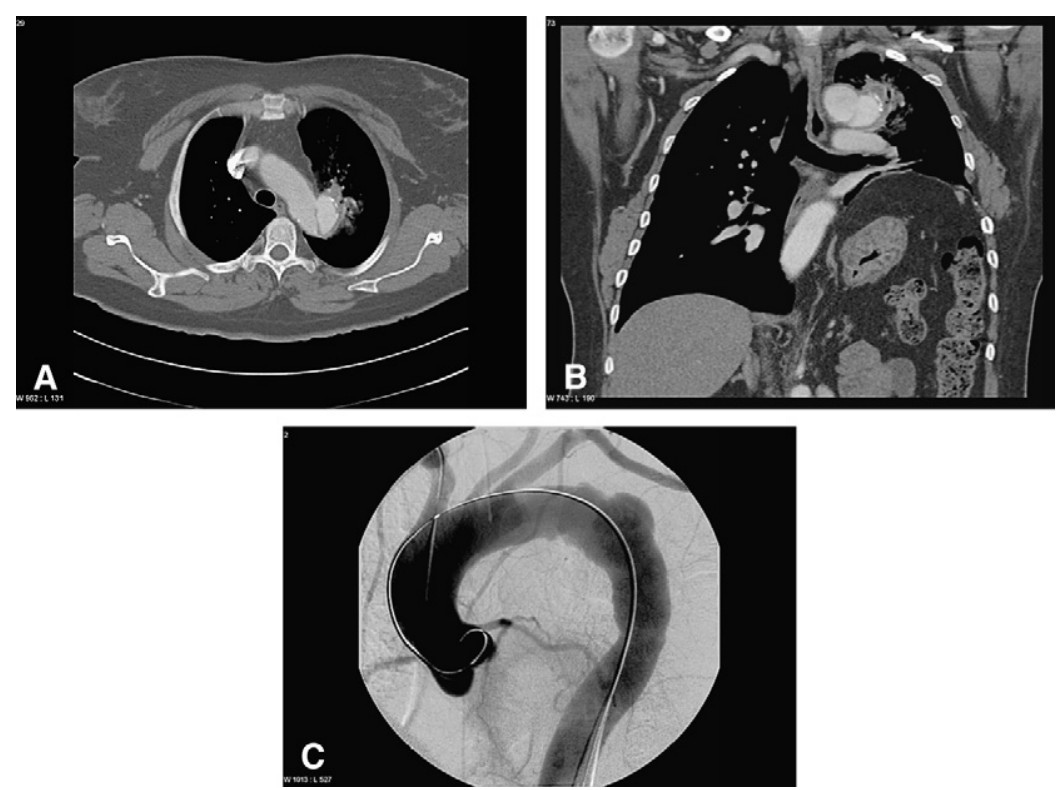

FIGURE 1. A and B, Initial chest CT showed a perforating ulcus of the descending aorta with connection to the bronchial system, leading to the diagnosis of an $\mathrm{ABF}$. C, Baseline angiography was performed before stent grafting. 

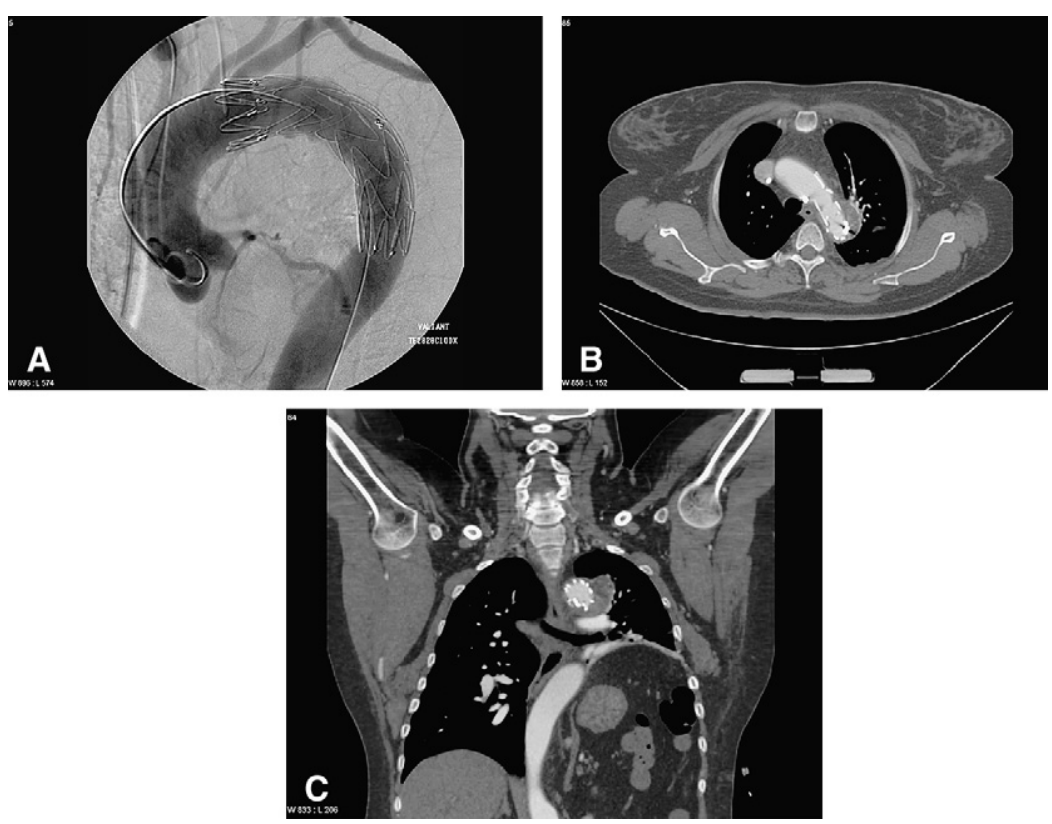

FIGURE 2. A, Control angiography of the aortic arch after stent placement and successful exclusion of both ulcers. B and C, Follow-up CT showed optimal situation of the stent graft and complete thrombosis of the false lumen.

tree. ${ }^{2}$ Acute or massive hemoptyses are the leading symptom and should lead to urgent radiologic assessment using contrast-enhanced CT. More invasive methods (eg, bronchoscopy or diagnostic angiography) may lead to clot instability and substantial blood loss. Until recently, open surgical repair was deemed the only treatment option for patients with ABFs. Yet, mortality rates of $15.3 \%$, mainly because of the complexity of procedures and emergency conditions, were reported. ${ }^{3}$ During the past years, endovascular repair of postoperative ABFs was considered to be a safe and less-invasive alternative. ${ }^{4,5}$

We report the case of an ABF occurring 27 years after open aortic surgery. Replacement of the descending aorta was necessary because of multiple trauma 9 years earlier that led to the development of a false aneurysm.

\section{CONCLUSIONS}

ABFs may develop even many years after surgery for aortic repair. Patients with hemoptysis and positive history for thoracic surgery require emergency diagnosis and immediate repair because untreated ABFs are uniformly fatal. $^{3}$ Endovascular intervention and stent grafting are feasible and should be the first option in the treatment of ABFs.

\section{References}

1. Nishizawa J, Matsumoto M, Sugita T, Matsuyama K, Tokuda Y, Yoshida K, et al. Surgical treatment of five patients with aortobronchial fistula in the aortic arch. Ann Thorac Surg. 2004;77:1821-3.

2. Pirrelli S, Bozzani A, Arici V, Odero A. Endovascular treatment of acute haemoptysis secondary to aortobronchial fistula. Eur J Vasc Endovasc Surg. 2006; 32:366-8.

3. Piciche M, De Paulis R, Fabbri A, Chiariello L. Postoperative aortic fistulas into the airways: etiology, pathogenesis, presentation, diagnosis, and management. Ann Thorac Surg. 2003;75:1998-2006.

4. Kokotsakis J, Misthos P, Athanasiou T, Romana C, Skouteli E, Lioulias A, et al. Endovascular stenting for primary aortobronchial fistula in association with massive hemoptysis. Tex Heart Inst J. 2007;34:369-72.

5. Quintana AL, Aguilar EM, Heredero AF, Riambau V, Paul L, Acin F. Aortobronchial fistula after aortic coartactation. I Thorac Cardiovasc Surg. 2006; 131:240-3. 